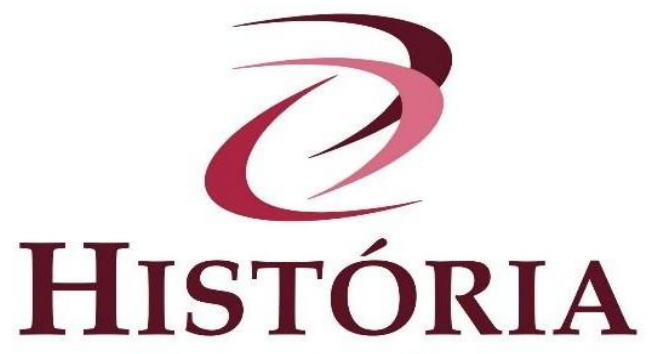

debates e tendências

\title{
SUMÁRIO / SUMMARY / SPIS TREŚCI
}

\section{Dossiê - Brasil-Polônia: Diálogos Histórico-Culturais* \\ Dossier - Brazil-Poland: historical-cultural dialogues}

Publikacja tematyczna - Brazylia-Polska: dialogi historyczno-kulturowe

\section{Editorial}

Fabricio J. Nazzari Vicroski (Universidade de Passo Fundo, Brasil)

Józef Szykulski (Uniwersytet Wrocławski, Polska)

(Mensagem do Embaixador Hadil da Rocha Vianna)

Na fronteira Brasil - Polônia: cooperação acadêmica em Antropologia Forense a serviço dos Direitos Humanos

At the Brazilian - Polish border: scientific cooperation in the field of forensic anthropology in the service of Human Rights

Na granicy Brazylijsko - Polskiej: współpraca naukowa w dziedzinie antropologii sądowej w służbie prawom człowieka

Katarzyna Górka, Academia Polonesa de Ciências, Polônia

Cláudia Regina Plens, Universidade Federal de São Paulo, Brasil

Pedidos de Extradição Formulados pela Polônia Contra Criminosos Nazistas Residentes no Brasil

Extradition Requests by Poland Against Nazi Criminals Residing in Brazil

Polskie wnioski o ekstradycję nazistowskich zbrodniarzy przebywającym w Brazylii

Felipe Cittolin Abal, Universidade de Passo Fundo, Brasil

Polonidade no Brasil: papel dos atores sociais e das instituições na manutenção e/ou extinção do patrimônio cultural

Polonity in Brazil: the role of social actors and institutions in the maintenance and /or extinction of cultural heritage

Polskość w Brazylii: rola aktorów społecznych oraz instytucji obywatelskich w

kultywowaniu i/lub zanikaniu dziedzictwa kulturowego

Schirlei Mari Freder, Pontifícia Universidade Católica do Paraná, Brasil 
Iniciativas Escolares Polonesas - Polskie szkoły no Brasil e a atuação do consulado no pós-reunificação polonesa: discursos e negociações culturais e identitárias.

Polish school initiatives - Polskie szkoły in Brazil and role of the consulate in polish postreunification: speeches and cultural and identity negotiations.

Polskie inicjatywy szkolne w Brazylii a rola konsulatu po zjednoczeniu Polski:

przemówienia i negocjacje kulturowo-tożsamościowe.

Fabiana Regina da Silva, Universidade Federal de Santa Maria, Brasil

86-114

A União Central dos Poloneses do Brasil e a imposição cultural nacional (1930 - 1938)

The Central Union of Poles in Brazil and the national cultural imposition (1930 - 1938)

Centralny Związek Polaków w Brazylii a narzucanie kultury narodowej (1930-1938)

Adriano Malikoski, Universidade de Caxias do Sul, Brasil

115-134

A educação polonesa na Colônia Erechim: a escola como instrumento de organização e resistência

Polish education in Colônia Erechim: school as an instrument of organization and

resistence

Edukacja polska w Kolonii Erechim: szkoła jako instrument organizacji i oporu

Isabel Rosa Gritti, Universidade Federal da Fronteira Sul, Brasil

Silvana Maria Gritti, Universidade Federal do Pampa, Brasil

Cultura, identidade(s) e memória na imigração polonesa no Rio Grande do Sul

135-152

Culture, identity(s) and memory in Polish immigration in Rio Grande do Sul

Kultura, tożsamość i pamięć w polskiej imigracji regionu Rio Grande do Sul

Thaís Janaina Wenczenovicz, Universidade Estadual do Rio Grande do Sul, Brasil

153-174

Poloneses no Espírito Santo: duas trajetórias de um povo entre os vales da Serra e os sertões do Norte

Poles in Espírito Santo: two trajectories of a people between the valleys of the Sierra and the hinterlands of the North

Polacy w Espírito Santo: dwie historie imigrantów w dolinach Serra i w interiorze Północy

Maria Cristina Dadalto, Universidade Federal do Espírito Santo, Brasil

Renata Siuda-Ambroziak, Universidade de Varsóvia, Polônia / UERJ

175-190

Brazylia Tomasza Łychowskiego

Brazil by Tomasz Łychowski

O Brasil de Tomasz Łychowski

Magdalena Bąk, Universidade da Silésia, Polônia 
O narrador sensível

The Tender Narrator

Czuły narrator

Olga Tokarczuk, Nobel de Literatura em 2019

Alcione Nawroski, Universidade Federal de Santa Catarina, Brasil

\section{Artigos Livres / Free Article / Oddzielne Artykuły}

210-228

Necropolítica austral: modernidade, guerra e nação na Argentina do século XIX Austral necropolitics: modernity, war and nation in nineteenth-century Argentina Necropolítica austral: modernidad, guerra y nación en la Argentina del siglo XIX Fabio Feltrin Souza, Universidade Federal da Fronteira Sul, Brasil

229-261

O Príncipe de Maquiavel como fonte histórica

The Prince of Machiavelli as a historical source

El Príncipe de Maquiavelo como fuente histórica

José Costa D'Assunção Barros, Universidade Federal Rural do Rio de Janeiro, Brasil

262-279

Quilombos em Minas Gerais: a titulação em terras de interesse transnacional

Quilombos in Minas Gerais: land ownership of transnational interest

Quilombos en Minas Gerais: el título de tierras de interés transnacional

Claudelir Correa Clemente, Universidade Federal de Uberlândia em Minas Gerais, Brasil

(*) Imagem da Capa/ Okladka: Símbolo da Águia Branca (brasão da Polônia), sob o Cruzeiro do Sul (Orzeł Biały pod Krzyżem Potudnia). A presente composição representa a presença da diáspora polonesa na América do Sul. (Okładka przedstawia obecność Polonii $w$ Ameryce Poludniowej).

Fontes das imagens/Źródła: Domínio público/ Domena publiczna.

Arte Final para a revista/opracowanie graficzne: Daniela Boscatto 